\title{
AÇÃO DA ACUPUNTURA NO SINTOMA DE FOGACHOS EM MULHERES APÓS CÂNCER DE MAMA: REVISÃO INTEGRATIVA
}

\section{ACUPUNCTURE ACTION ON HOT FLASHES IN WOMEN AFTER BREAST CANCER: AN INTEGRATIVE REVIEW}

\section{ACCIÓN DE LA ACUPUNTURA SOBRE LOS SÍNTOMAS DE SOFOCOS EN MUJERES DESPUÉS DE CÁNCER DE MAMA: REVISIÓN INTEGRATIVA}

Nazir Felippe Gomes ${ }^{1}$, Bianca Bacelar de Assis², Caroline de Castro Moura ${ }^{3}$, Cissa Azevedo ${ }^{4}$, Joloano Nasser Raydan Viana ${ }^{5}$, Tânia Couto Machado Chianca ${ }^{6}$

\section{RESUMO}

Objetivo: Investigar evidências, na literatura, acerca da ação da acupuntura no sintoma de fogachos em mulheres, após câncer de mama e estabelecer um protocolo para o tratamento dessa condição. Método: Revisão integrativa, conduzida em agosto de 2019. Utilizaram-se bases de dados nacionais e internacionais. Resultados: Foram encontradas 288 pesquisas e 11 foram incluídas no estudo. A acupuntura demonstrou resultados positivos sobre os sintomas de fogachos. Não há padronização no tratamento, porém um possível protocolo foi proposto: realização da acupuntura sistêmica ou eletroacupuntura nos acupontos Baço 6, Fígado 3, Rim 3, Circulação sexo 6, Vaso concepção 4, Bexiga 23 e Vaso Governador 20, agulhas sistêmicas que devem ser manipuladas até obter a sensação De qi, 10 sessões, uma ou duas vezes por semana, com retenção das agulhas nos acupontos em aproximadamente 25 minutos. Conclusão: a acupuntura parece ser uma intervenção efetiva para o tratamento e controle dos fogachos em mulheres, após câncer de mama e consiste em uma opção terapêutica a qual o enfermeiro pode executar de maneira autônoma e independente em todos os níveis de atenção. Torna-se necessária a realização de ensaios clínicos randomizados com a utilização do protocolo proposto a fim de validá-lo.

Descritores: Acupuntura; Câncer de Mama; Fogachos.

\section{ABSTRACT}

Aim: to investigate evidence in the literature about the action of acupuncture on hot flashes in women after breast cancer and to establish a protocol for the treatment of this condition. Method: an integrative review of national and international databases conducted in August 2019. Results: 288 studies were found and 11 were included in this study. Acupuncture has shown positive results on the symptoms of hot flashes. Even though there is no standardization in treatment, the following protocol was proposed: a) performing systemic acupuncture or electroacupuncture in acupoints Spleen 6, Liver 3, Kidney 3, Circulation sex 6, Conception vessel 4, Bladder 23 and Governor vessel 20, b) systemic needles should be manipulated until the patient gets the De qi sensation, c) 10 sessions, once or twice a week, with needles retained in the acupoints for approximately 25 minutes. Conclusion: acupuncture appears to be an effective intervention for the treatment and control of hot flashes in women after breast cancer. In addition, it is a qualified therapeutic option which nurses can perform autonomously and independently at all levels of care. Further randomized clinical trials are necessary to validate the proposed protocol.

Descriptors: Acupuncture; Breast Cancer; Hot Flashes.

\section{RESUMEN}

Objetivo: investigar la evidencia en la literatura sobre la acción de la acupuntura en los síntomas de sofocos en mujeres después del cáncer de mama y establecer un protocolo para el tratamiento de esta afección. Método: una revisión integradora realizada en agosto de 2019. Se utilizaron bases de datos nacionales e internacionales. Resultados: se encontraron 288 búsquedas y se incluyeron 11 en el estudio. La acupuntura ha mostrado resultados positivos en los síntomas de los sofocos. No hay estandarización, no hay tratamiento, un posible protocolo: realizar acupuntura sistémica o electroacupuntura en puntos de acupuntura Bazo 6, Hígado 3 , Riñón 3, Circulación sexual 6, Vaso de concepción 4, Vejiga 23 y Vaso gobernador 20, agujas sistémicas que deberían ser manipuladas hasta obtener la sensación De qi, 10 sesiones, una o dos veces por semana, con agujas retenidas en los puntos de acupuntura durante aproximadamente 25 minutos. Conclusión: la acupuntura parece ser una intervención efectiva para el tratamiento y el control de los sofocos en mujeres después del cáncer de mama y es una opción terapéutica en la cual el enfermero puede actuar de forma autónoma e independiente en todos los niveles de atención. Fue necesario realizar ensayos clínicos aleatorios utilizando el protocolo propuesto con el fin de validarlo.

Descriptores: Acupuntura; Cáncer de Mama; Sofocos.

${ }^{1}$ Mestre em Patologia Geral. Diretor clínico da NF Fisioterapia e Coordenador do serviço de Fisioterapia Oncológica do Hospital Mater Dei. ${ }^{2}$ Doutoranda em Enfermagem pelo Programa de Pós-Graduação em Enfermagem da Universidade Federal de Minas Gerais. ${ }^{3}$ Doutora em Enfermagem. Professor Adjunto da Universidade Federal de Viçosa. ${ }^{4}$ Doutoranda em Enfermagem pela Escola de Enfermagem da Universidade Federal de Minas Gerais. ${ }^{5}$ Psicólogo. Pós-graduação em acupuntura pela Faculdade INCISA/IMAM. ${ }^{6}$ Pós-Doutorado no Center for Nursing Classification do College of Nursing-The University of Lowa. Professor Titular do Departamento de Enfermagem Básica da Escola de Enfermagem da Universidade Federal de Minas Gerais. 


\section{INTRODUÇÃO}

O câncer pertence ao grupo de doenças não transmissíveis (DNTs) e, atualmente, é uma das principais causas de morte no mundo ${ }^{(1)}$. $O$ câncer de mama é responsável pela maioria da mortalidade entre as mulheres e é o segundo tipo mais comum ( $11,6 \%$ do total), estando atrás somente do câncer de pulmão(2).

O tratamento de mulheres com câncer de mama inclui modernos tipos de abordagens, dentre os quais se destaca a terapia endócrina. É um tratamento comum para alguns casos de câncer de mama e é acompanhado por vários efeitos colaterais, como intensas ondas de calor que desencadeiam fadiga, alterações na qualidade do sono e piora na qualidade de vida ${ }^{(3-4)}$.

As ondas de calor, também denominadas "fogachos", afetam de $64 \%$ a $85 \%$ das mulheres tratadas por câncer de mama ${ }^{(5)}$.

Diante do impacto significativo que esse sintoma ocasiona na vida dessas mulheres, é imprescindível buscar recursos terapêuticos para a melhora das condições de vida e saúde em longo prazo $^{(3)}$. Nesse cenário, destaca-se a acupuntura, uma opção não farmacológica para o tratamento das ondas de calor.

No âmbito oncológico, observa-se que a acupuntura é uma terapia segura e eficaz, ao atuar como coadjuvante no manejo da patologia e de sintomas relacionados ao tratamento ${ }^{(6)}$. A revisão sistemática evidenciou que a técnica atua como uma terapêutica complementar ao tratamento convencional para o controle de ondas de calor em mulheres na menopausa com câncer de mama ${ }^{(7)}$.

Diante da relevância da temática abordada, é importante que estudos possam esclarecer com mais propriedade o efeito da acupuntura no alívio e/ou redução das ondas de calor em pacientes que trataram o câncer de mama. Ademais, o aumento frequente do uso da acupuntura como forma de tratamento das ondas de calor deve ser avaliado com maior rigor para uma prática segura e eficiente.

Portanto, o objetivo do estudo é investigar as evidências disponíveis na literatura a respeito da ação da acupuntura no sintoma de fogachos em mulheres, após câncer de mama, e estabelecer um protocolo para o tratamento dessa condição clínica.

\section{MÉTODO}

Revisão integrativa da literatura conduzida em cinco etapas: identificação do problema, busca dos estudos primários na literatura, avaliação, análise dos dados e apresentação da revisão(8).

As questões norteadoras que guiaram a condução desta revisão foram: "Qual a ação da acupuntura no sintoma de fogachos em mulheres após o câncer de mama? Qual o protocolo de acupuntura utilizado para tratar essa condição?"

A busca pelos artigos foi feita por dois revisores independentes, em agosto de 2019, nas seguintes bases de dados: Medline via PUBMED, Web of Science, Physiotherapy Evidence Database (PEDro), Scopus, além da SCIELO e das Bibliotecas Virtuais em Saúde (BVS) e Medicinas Tradicionais, Complementares e Integrativas (BVS-MTCI). Listas de referências de outras investigações também foram exploradas na busca de estudos relevantes relacionados à questão norteadora.

Termos controlados, extraídos dos Descritores em Ciências da Saúde (DECS) e do Medical Subject Headings (MeSH), foram combinados, por meio do operador boleano AND da seguinte forma: (Acupuncture AND "breast neoplasms." AND "hot flashes"). A estratégia de busca foi adaptada para cada base eletrônica de dados e os termos foram pesquisados em todos os campos (título/resumo/descritores/texto).

Os critérios de elegibilidade para a seleção dos artigos foram ensaios clínicos randomizados ou estudos quase experimentais, publicados nos últimos 10 anos, ou seja, de 2009 a 2019, nos idiomas inglês, português ou espanhol. Foram excluídos os estudos que não responderam à questão norteadora, aqueles que não apresentaram resumo online na íntegra para análise ou que não foram localizados (online, via comutação bibliográfica - COMUT ou contato direto com os autores), literatura cinzenta (livros e monografias) e resumo de anais de eventos.

Os dados dos estudos foram extraídos, adotando-se um formulário elaborado pelos pesquisadores, sendo eles: identificação do estudo (autor(es)/ano de publicação); objetivos; características metodológicas (delineamento, tamanho da amostra, modalidade de acupuntura no grupo experimental, intervenção no grupo controle); protocolo de aplicação da acupuntura baseado nas recomendações do Revised Standards for Reporting Interventions in Clinical Trials of Acupuncture (STRICTA) $)^{(9)}$; principais resultados; e conclusões.

Todos os estudos incluídos na revisão foram classificados quanto ao nível de evidência com base na classificação proposta pela Evidencebased practice ${ }^{(10)}$. Essa análise foi conduzida por 
dois revisores independentes, com 100\% de concordância.

\section{RESULTADOS E DISCUSSÃO}

Foram encontrados 288 estudos nas buscas eletrônica e manual. Por estarem duplicados, 79 foram removidos da listagem. Após a revisão de títulos e resumos, 197 artigos foram excluídos, de forma que 12 permaneceram para a análise do texto completo. Desses, um estudo não foi localizado (online, via comutação bibliográfica ou contato direto com os autores). Dessa forma, 11 artigos foram incluídos na síntese da análise qualitativa (Figura 1).

Figura 1 - Fluxograma de seleção dos artigos da Revisão Integrativa. Belo Horizonte, MG, Brasil, 2019.
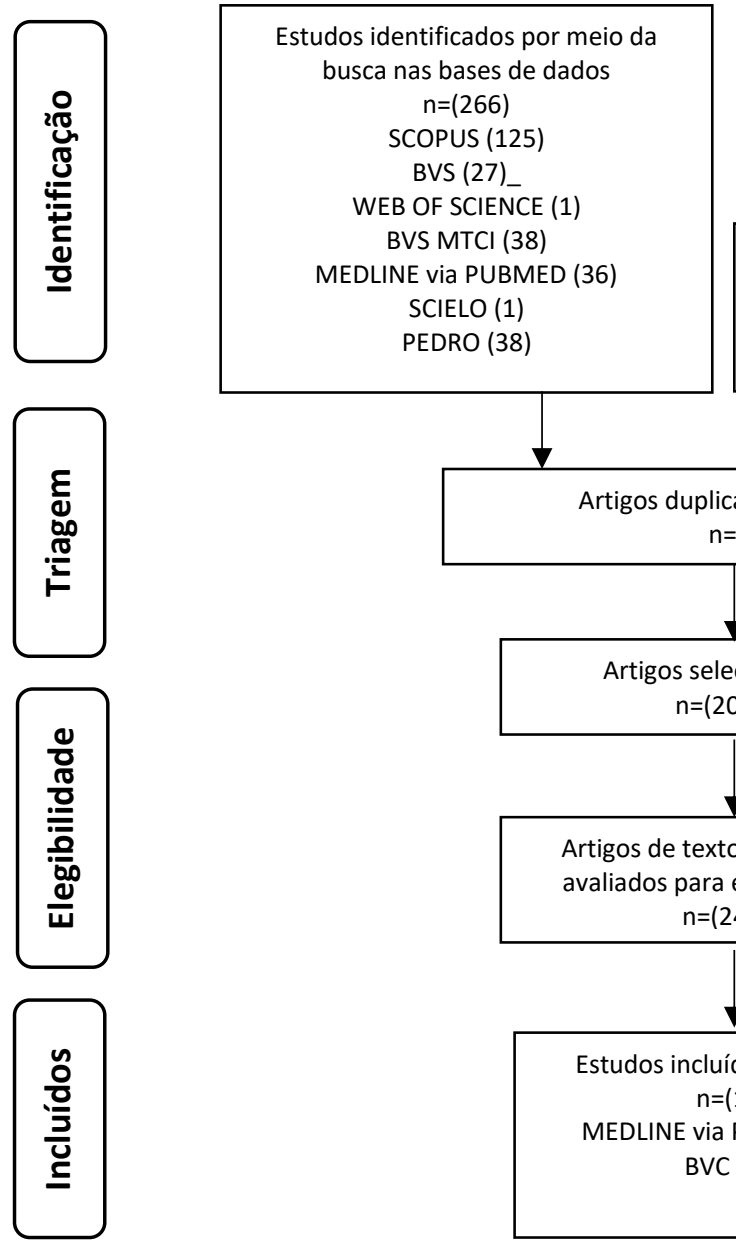

Artigos adicionais identificados por meio de outras fontes - Busca manual em listas de referências de outros estudos $n=(22)$

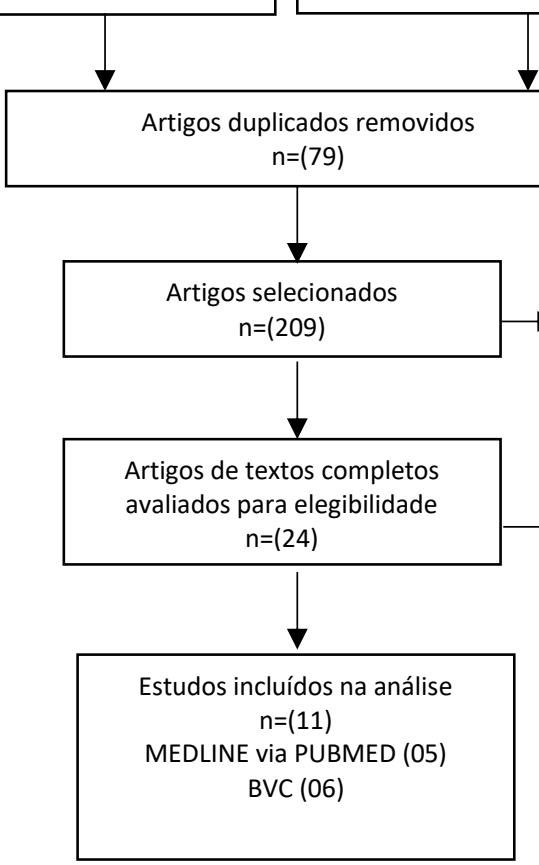

Fonte: Do autor.

Todas as publicações encontradas foram escritas em inglês e dois estudos foram realizados na Suécia ${ }^{(4,11)}$, quatro nos Estados Unidos ${ }^{(12-15)}$, um na Dinamarca ${ }^{(16)}$, um na Noruega ${ }^{(17)}$, um na Coreia do Sul ${ }^{(18)}$, um na Inglaterra ${ }^{(19)}$ e um na Itália ${ }^{(20)}$.

Dentre os periódicos em que os estudos foram publicados, oito são da área específica de oncologia $^{(4,11-14,16-17,20)}$, enquanto dois pertencem à temática de Medicina Complementar e Alternativa ${ }^{(18-19)}$, e um da área de enfermagem ${ }^{(15)}$.

Um total de 763 mulheres que apresentaram câncer de mama participaram dos estudos selecionados e a idade variou de $30^{(12)}$ a $85^{(13)}$ anos.

$\mathrm{Na}$ Figura 2, apresentam-se as características dos estudos incluídos na revisão. 
Figura 2 - Caracterização dos estudos. Belo Horizonte, 2020. (n=11)

\begin{tabular}{|c|c|c|c|c|c|c|c|}
\hline $\begin{array}{c}\text { Identificação } \\
\text { do estudo }\end{array}$ & Objetivo & Amostra & $\begin{array}{l}\text { Intervenção } \\
\text { no grupo } \\
\text { experimental }\end{array}$ & $\begin{array}{l}\text { Intervenção no } \\
\text { grupo controle }\end{array}$ & $\begin{array}{l}\text { Desfechos } \\
\text { avaliados }\end{array}$ & $\begin{array}{l}\text { Número de } \\
\text { avaliações }\end{array}$ & $\begin{array}{l}\text { Principais } \\
\text { achados }\end{array}$ \\
\hline $\begin{array}{l}\text { LESI et al. } \\
2016^{(20)}\end{array}$ & $\begin{array}{l}\text { Determinar a } \\
\text { eficácia da } \\
\text { acupuntura } \\
\text { para o manejo } \\
\text { de ondas de } \\
\text { calor em } \\
\text { mulheres com } \\
\text { câncer de } \\
\text { mama }\end{array}$ & $\begin{array}{c}190 \\
\text { mulheres }\end{array}$ & $\begin{array}{c}\text { Acupuntura } \\
\text { sistêmica }+ \\
\text { autocuidado }\end{array}$ & $\begin{array}{c}\text { Autocuidado } \\
\text { (folheto com } \\
\text { informações sobre } \\
\text { ondas de calor e } \\
\text { câncer; e } \\
\text { recomendações } \\
\text { sobre dieta, } \\
\text { exercícios físicos e } \\
\text { apoio psicológico) }\end{array}$ & $\begin{array}{l}\text { Pontuação média } \\
\text { de fogachos } \\
\text { diários, sintomas } \\
\text { do climatério } \\
\text { (Greene } \\
\text { Climacteric Scale) } \\
\text { e qualidade de } \\
\text { vida (Menopause } \\
\text { Quality of Life - } \\
\text { MenQol) }\end{array}$ & $\begin{array}{c}04 \text { (1 semana } \\
\text { antes da } \\
\text { randomiza- } \\
\text { ção, semana } \\
12 \text {, follow up } \\
\text { de } 03 \text { e } 06 \\
\text { meses) }\end{array}$ & $\begin{array}{c}\text { A acupuntura } \\
\text { associada ao } \\
\text { autocuidado é } \\
\text { uma intervenção } \\
\text { eficaz para o } \\
\text { manejo de ondas } \\
\text { de calor e } \\
\text { melhora da } \\
\text { qualidade de vida } \\
\text { em mulheres } \\
\text { com câncer de } \\
\text { mama. }\end{array}$ \\
\hline $\begin{array}{l}\text { MAO et al. } \\
2015^{(12)}\end{array}$ & $\begin{array}{c}\text { Avaliar os } \\
\text { efeitos da } \\
\text { eletroacupun- } \\
\text { tura versus } \\
\text { gabapentina } \\
\text { para ondas de } \\
\text { calor entre } \\
\text { mulheres com } \\
\text { câncer de } \\
\text { mama }\end{array}$ & $\begin{array}{c}120 \\
\text { mulheres }\end{array}$ & $\begin{array}{l}\text { Eletro- } \\
\text { acupuntura } \\
\text { sistêmica }\end{array}$ & $\begin{array}{c}3 \text { grupos } \\
\text { controles: } \\
\text { Acupuntura Sham } \\
\text { (SA) - } \\
\text { puntura } \\
\text { modificada sem } \\
\text { eletroestimulação } \\
; \\
\text { Gabapentina (GP) } \\
\text { - pílulas de 300 } \\
\text { mg; Placebo da } \\
\text { gabapentina (PP) } \\
\text { - cápsulas de } \\
\text { placebo }\end{array}$ & \begin{tabular}{|c|} 
Hot Flash \\
Composite \\
Score(HFCS) uma \\
vez por semana, \\
conforme medido \\
pelo Daily Hot \\
Flash Diary. A \\
equipe de \\
pesquisa cegou \\
para eventos \\
adversos \\
monitorados (AEs) \\
de atribuição de \\
tratamento \\
usando um \\
formulário de \\
relatório de caso \\
de EA padrão toda \\
semana durante a \\
fase de \\
intervenção.
\end{tabular} & \begin{tabular}{|c} 
\\
\\
4 (inicial, na \\
8 a semana - \\
avaliação \\
final e follow \\
up de 12 e 24 \\
semanas) \\
\\
\end{tabular} & $\begin{array}{c}\text { A acupuntura } \\
\text { produziu maior } \\
\text { placebo e } \\
\text { menores efeitos } \\
\text { nocebo do que } \\
\text { pílulas para o } \\
\text { tratamento de } \\
\text { ondas de calor. A } \\
\text { Eletroacupuntura } \\
\text { pode ser mais } \\
\text { eficaz que a } \\
\text { Gabapentina, } \\
\text { com menos } \\
\text { efeitos adversos } \\
\text { para o } \\
\text { gerenciamento } \\
\text { de ondas de calor } \\
\text { entre os } \\
\text { sobreviventes de } \\
\text { câncer de mama. }\end{array}$ \\
\hline $\begin{array}{c}\text { BAO et al. } \\
2014^{(13)}\end{array}$ & $\begin{array}{l}\text { Avaliar se a } \\
\text { acupuntura } \\
\text { real, em } \\
\text { comparação } \\
\text { com a } \\
\text { acupuntura } \\
\text { sham, melhora } \\
\text { os resultados } \\
\text { relatados } \\
\text { pelos } \\
\text { pacientes com } \\
\text { câncer de } \\
\text { mama em uso } \\
\text { de inibidores } \\
\text { de aromatase } \\
\text { adjuvante }\end{array}$ & 51 mulheres & $\begin{array}{l}\text { Acupuntura } \\
\text { sistêmica }\end{array}$ & $\begin{array}{c}\text { Agulhas retráteis e } \\
\text { não penetrantes, } \\
\text { colocadas em } 14 \\
\text { pontos de } \\
\text { acupuntura sham, } \\
\text { localizados no } \\
\text { ponto médio da } \\
\text { linha que conecta } \\
\text { dois acupontos } \\
\text { reais. }\end{array}$ & \begin{tabular}{|} 
Questionário de \\
sintomas de \\
menopausa \\
Adjuvante \\
Cirúrgico de \\
Mama e Intestino, \\
Escala de \\
Depressão de \\
Estudos \\
Epidemiológicos, \\
Escala Hospitalar \\
de Ansiedade e \\
Depressão, Índice \\
de Qualidade do \\
Sono de \\
Pittsburgh, diário \\
de ondas de calor, \\
Escala de \\
Interferência \\
Diária Relacionada \\
com ondas de \\
calor, Inquérito \\
Europeu de \\
Qualidade de Vida
\end{tabular} & \begin{tabular}{|c} 
\\
\\
4 (inicial, \\
após 4a \\
semana \\
durante o \\
tratamento; \\
8a semana e \\
follow up de \\
12 semanas) \\
\end{tabular} & $\begin{array}{l}\text { A acupuntura real } \\
\text { e a acupuntura } \\
\text { sham foram } \\
\text { associadas à } \\
\text { melhora em } \\
\text { pacientes com } \\
\text { câncer de mama } \\
\text { em uso de } \\
\text { inibidores de } \\
\text { aromatase, e } \\
\text { nenhuma } \\
\text { diferença } \\
\text { significativa foi } \\
\text { detectada entre } \\
\text { os grupos. }\end{array}$ \\
\hline
\end{tabular}




\begin{tabular}{|c|c|c|c|c|c|c|c|}
\hline $\begin{array}{c}\text { Identificação } \\
\text { do estudo }\end{array}$ & Objetivo & Amostra & $\begin{array}{l}\text { Intervenção } \\
\text { no grupo } \\
\text { experimental }\end{array}$ & $\begin{array}{l}\text { Intervenção no } \\
\text { grupo controle }\end{array}$ & $\begin{array}{l}\text { Desfechos } \\
\text { avaliados }\end{array}$ & $\begin{array}{l}\text { Número de } \\
\text { avaliações }\end{array}$ & $\begin{array}{l}\text { Principais } \\
\text { achados }\end{array}$ \\
\hline $\begin{array}{l}\text { BOKMAND; } \\
\text { FLYGER, } \\
2013^{(16)}\end{array}$ & 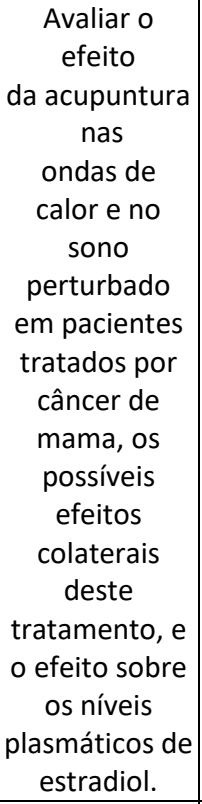 & 94 mulheres & $\begin{array}{l}\text { Acupuntura } \\
\text { sistêmica }\end{array}$ & $\begin{array}{c}2 \text { grupos controle: } \\
\text { sem intervenção; } \\
\text { Acupuntura Sham } \\
\text { - quatro pontos } \\
\text { bilaterais fora dos } \\
\text { meridianos, mas } \\
\text { na mesma região } \\
\text { dos pontos } \\
\text { verdadeiros. } \\
\text { Foram utilizadas } \\
\text { as mesmas } \\
\text { agulhas que a } \\
\text { acupuntura } \\
\text { verdadeira e } \\
\text { inseridas } \\
\text { superficialmente } \\
\text { na pele. }\end{array}$ & \begin{tabular}{|} 
Intensidade dos \\
sintomas por \\
meio de escala \\
visual analógica \\
graduada de zero \\
a dez; os \\
distúrbios do sono \\
foram \\
classificados como \\
"sim" ou "não"; e \\
nível de estradiol \\
no plasma
\end{tabular} & $\begin{array}{c}8 \text { avaliações } \\
\text { (2 semanas } \\
\text { antes do } \\
\text { tratamento; } \\
5 x \text { durante o } \\
\text { tratamento; } 6 \\
\text { e } 12 \text { semanas } \\
\text { após o início } \\
\text { do } \\
\text { tratamento). } \\
\text { O nível de } \\
\text { estradiol foi } \\
\text { avaliado } 3 x: \\
\text { antes do } 10 \\
\text { tratamento, } \\
30 \text { minutos } \\
\text { depois e após } \\
5 \text { semanas. }\end{array}$ & $\begin{array}{c}\text { A acupuntura } \\
\text { alivia } \\
\text { significativament } \\
\text { e as ondas de } \\
\text { calor e distúrbios } \\
\text { do sono e é um } \\
\text { tratamento bom } \\
\text { e seguro em } \\
\text { mulheres } \\
\text { tratadas para } \\
\text { câncer de mama. } \\
\end{array}$ \\
\hline $\begin{array}{c}\text { JEONG et al. } \\
2013^{(18)}\end{array}$ & $\begin{array}{c}\text { Avaliar a } \\
\text { viabilidade e a } \\
\text { segurança } \\
\text { da acupuntura } \\
\text { para } \\
\text { tratamento de } \\
\text { ondas de calor } \\
\text { em pacientes } \\
\text { com câncer de } \\
\text { mama } \\
\text { recebendo } \\
\text { terapia } \\
\text { antiestrogênic } \\
\text { a } \\
\end{array}$ & 10 mulheres & $\begin{array}{l}\text { Acupuntura } \\
\text { sistêmica }\end{array}$ & // & $\begin{array}{l}\text { Gravidade dos } \\
\text { fogachos } \\
\text { avaliados por } \\
\text { escala visual } \\
\text { analógica e } \\
\text { pontuação total } \\
\text { de fogachos. }\end{array}$ & $\begin{array}{c}06 \text { (1 semana } \\
\text { antes do } \\
\text { início do } \\
\text { tratamento, } \\
1 \times / \text { semana } \\
\text { durante o } \\
\text { tratamento e } \\
4 \text { semanas } \\
\text { após a sessão } \\
\text { final de } \\
\text { acupuntura) }\end{array}$ & $\begin{array}{l}\text { A acupuntura } \\
\text { pareceu } \\
\text { proporcionar um } \\
\text { alívio efetivo das } \\
\text { ondas de calor e } \\
\text { os efeitos } \\
\text { duraram pelo } \\
\text { menos um mês } \\
\text { após o término } \\
\text { do tratamento. }\end{array}$ \\
\hline $\begin{array}{l}\text { FRISK et al. } \\
2012^{(4)}\end{array}$ & 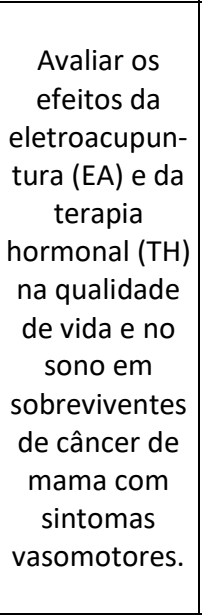 & 45 mulheres & $\begin{array}{l}\text { Eletro- } \\
\text { acupuntura } \\
\text { sistêmica }\end{array}$ & $\begin{array}{c}\text { Terapia } \\
\text { combinada de } \\
\text { estrogênio / } \\
\text { progesterona }\end{array}$ & \begin{tabular}{|c|} 
Escores de \\
Fogachos; \\
Qualidade de vida \\
relacionada à \\
saúde; Diários \\
com os números \\
de ondas de calor \\
por dia e noite e \\
angústia causada \\
devido às ondas \\
de calor; \\
Questionário de \\
Saúde da Mulher; \\
Índice de Bem- \\
Estar Psicológico e \\
Geral.
\end{tabular} & \begin{tabular}{|c|}
7 (Inicial, 12a \\
semana - \\
avaliação \\
final e Follow- \\
up: 6, 9, 12, \\
18 e 24 \\
meses) \\
\end{tabular} & $\begin{array}{c}\text { Tanto a EA } \\
\text { quanto a TH } \\
\text { melhoraram a } \\
\text { qualidade de vida } \\
\text { e o sono. Embora } \\
\text { as ondas de calor } \\
\text { tenham } \\
\text { diminuído menos } \\
\text { no grupo EA do } \\
\text { que no grupo TH, } \\
\text { a qualidade de } \\
\text { vida melhorou } \\
\text { pelo menos na } \\
\text { mesma medida. }\end{array}$ \\
\hline
\end{tabular}




\begin{tabular}{|c|c|c|c|c|c|c|c|}
\hline $\begin{array}{l}\text { Identificação } \\
\text { do estudo }\end{array}$ & Objetivo & Amostra & $\begin{array}{c}\text { Intervenção } \\
\text { no grupo } \\
\text { experimental }\end{array}$ & $\begin{array}{l}\text { Intervenção no } \\
\text { grupo controle }\end{array}$ & $\begin{array}{l}\text { Desfechos } \\
\text { avaliados }\end{array}$ & $\begin{array}{l}\text { Número de } \\
\text { avaliações }\end{array}$ & $\begin{array}{l}\text { Principais } \\
\text { achados }\end{array}$ \\
\hline $\begin{array}{c}\text { LILJEGREN } \\
\text { et al. 2012 }\end{array}$ & $\begin{array}{c}\text { Avaliar a ação } \\
\text { da acupuntura } \\
\text { verdadeira em } \\
\text { comparação } \\
\text { com } \\
\text { estimulação } \\
\text { não-invasiva } \\
\text { em pontos } \\
\text { falsos sobre } \\
\text { ondas de calor } \\
\text { e suores em } \\
\text { mulheres com } \\
\text { câncer de } \\
\text { mama } \\
\text { tratadas com } \\
\text { tamoxifeno } \\
\text { adjuvante. }\end{array}$ & \begin{tabular}{|l|}
84 mulheres \\
8
\end{tabular} & $\begin{array}{l}\text { Acupuntura } \\
\text { sistêmica }\end{array}$ & $\begin{array}{c}\text { Agulhas sham - } \\
\text { agulhas foram } \\
\text { aplicadas a } 1 \mathrm{~cm} \\
\text { de distância dos } \\
\text { pontos usados } \\
\text { no grupo de } \\
\text { acupuntura } \\
\text { verdadeira, sem } \\
\text { colocá-los em } \\
\text { um meridiano ou } \\
\text { ponto } \\
\text { diferente. As } \\
\text { agulhas foram } \\
\text { colocadas, mas } \\
\text { não penetraram } \\
\text { na pele. As } \\
\text { agulhas foram } \\
\text { giradas até o } \\
\text { paciente sentir } \\
\text { sensação } \\
\text { superficial } \\
\text { cutânea, após } 10 \\
\text { minutos e antes } \\
\text { da retirada das } \\
\text { agulhas. } \\
\end{array}$ & \begin{tabular}{|c|} 
Sintomas \\
vasomotores \\
(ondas de calor e \\
frequências de \\
transpiração), \\
avaliados por meio \\
de escala verbal \\
graduada em 'sem \\
problemas, leve, \\
moderada, grave \\
ou muito grave'. \\
Diário - incidência \\
e gravidade dos \\
fogachos e suor \\
durante o dia e \\
noite. Níveis \\
circulantes de \\
estradiol, \\
progesterona, \\
testosterona, \\
prolactina, \\
hormônio folículo \\
estimulante, \\
hormônio \\
luteinizante e \\
globulina de ligação \\
a hormônios \\
sexuais.
\end{tabular} & \begin{tabular}{|c|}
4 (Inicial; 3a \\
semana \\
durante o \\
tratamento; \\
6a semana - \\
avaliação \\
final e follow- \\
up na 18a \\
semana)
\end{tabular} & $\begin{array}{c}\text { A acupuntura } \\
\text { verdadeira é mais } \\
\text { eficaz do que a } \\
\text { acupuntura sham } \\
\text { na redução dos } \\
\text { sintomas } \\
\text { vasomotores. }\end{array}$ \\
\hline $\begin{array}{l}\text { OTTE et al. } \\
2011^{(15)}\end{array}$ & $\begin{array}{c}\text { Analisar a } \\
\text { viabilidade da } \\
\text { acupuntura } \\
\text { em } \\
\text { sobreviventes } \\
\text { de câncer de } \\
\text { mama na pós- } \\
\text { menopausa } \\
\text { que relatam } \\
\text { distúrbios do } \\
\text { sono e ondas } \\
\text { de calor. } \\
\text { Dentre os } \\
\text { objetivos: } \\
\text { descrever } \\
\text { padrões de } \\
\text { uso do ponto } \\
\text { de } \\
\text { acupuntura; } \\
\text { avaliar } \\
\text { expectativa de } \\
\text { resultado, } \\
\text { credibilidade e } \\
\text { aceitabilidade } \\
\text { em relação à } \\
\text { intervenção; e } \\
\text { avaliar } \\
\text { padrões de } \\
\text { mudança de } \\
\text { sintomas ao } \\
\text { longo do } \\
\text { tempo. }\end{array}$ & 10 mulheres & $\begin{array}{l}\text { Acupuntura } \\
\text { sistêmica }\end{array}$ & // & \begin{tabular}{|c|} 
Expectativa e \\
credibilidade dos \\
resultados; \\
aceitação em \\
relação à \\
intervenção; \\
monitoramento \\
fisiológico usando \\
actigrafia de pulso \\
(mede a atividade \\
do sono e do \\
despertar através \\
do movimento do \\
pulso); Diário do \\
sono (tempo para \\
dormir, tempo fora \\
da cama e os \\
cochilos); qualidade \\
do sono e \\
distúrbios - \\
Pittsburgh Sleep \\
Quality Index; \\
Monitorização da \\
Condutância da \\
Pele (frequência \\
fisiológica de ondas \\
de calor); \\
Interferência \\
percebida dos \\
fogachos (The Hot \\
Flash Related Daily \\
Interference Scale).
\end{tabular} & $\begin{array}{c}05 \text { (antes do } \\
\text { início do } \\
\text { tratamento, } \\
\text { durante o } \\
\text { tratamento } \\
\text { (semanas 3, } \\
\text { 4) e após o } \\
\text { tratamento } \\
\text { (semanas 5, } \\
\text { 8) }\end{array}$ & $\begin{array}{c}\text { O tratamento } \\
\text { com acupuntura } \\
\text { parece ser uma } \\
\text { opção de } \\
\text { tratamento viável } \\
\text { para mulheres } \\
\text { com câncer de } \\
\text { mama na pós- } \\
\text { menopausa, com } \\
\text { distúrbios do } \\
\text { sono e ondas de } \\
\text { calor. }\end{array}$ \\
\hline
\end{tabular}




\begin{tabular}{|c|c|c|c|c|c|c|c|}
\hline $\begin{array}{l}\text { Identificação } \\
\text { do estudo }\end{array}$ & Objetivo & Amostra & $\begin{array}{l}\text { Intervenção } \\
\text { no grupo } \\
\text { experimental }\end{array}$ & $\begin{array}{l}\text { Intervenção no } \\
\text { grupo controle }\end{array}$ & $\begin{array}{l}\text { Desfechos } \\
\text { avaliados }\end{array}$ & $\begin{array}{l}\text { Número de } \\
\text { avaliações }\end{array}$ & $\begin{array}{l}\text { Principais } \\
\text { achados }\end{array}$ \\
\hline \begin{tabular}{c|} 
WALKER \\
et al. 2010(14) \\
\end{tabular} & \begin{tabular}{|c|} 
Avaliar o \\
efeito da \\
acupuntura na \\
redução/elimi- \\
nação dos \\
sintomas \\
vasomotores \\
em pacientes \\
com câncer de \\
mama que \\
receberam \\
terapia com \\
hormônio anti- \\
estrogênio em \\
comparação \\
com \\
venlafaxina; \\
determinar se \\
a acupuntura \\
tem menos \\
efeitos \\
adversos.
\end{tabular} & 50 mulheres & $\begin{array}{l}\text { Acupuntura } \\
\text { sistêmica }\end{array}$ & \begin{tabular}{|c|} 
Uso de \\
venlaflaxina 37,5 \\
mg por via oral à \\
noite por 1 \\
semana, depois 75 \\
mg à noite pelas \\
11 semanas \\
restantes.
\end{tabular} & \begin{tabular}{|} 
Diário de ondas \\
de calor - \\
mensurou o \\
número e \\
gravidade das \\
ondas de calor; \\
Questionário de \\
Qualidade de \\
Vida Específica da \\
Menopausa; \\
Short Form 12 - \\
Item Survey- \\
mediu o estado \\
geral de saúde; \\
Inventário de \\
Depressão de \\
Beck; Escala dos \\
critérios comuns \\
de toxicidade do \\
Instituto Nacional \\
do Câncer mediu \\
os efeitos \\
adversos do \\
tratamento. \\
\end{tabular} & \begin{tabular}{|c} 
\\
\\
6 (1 semana \\
antes do \\
tratamento; \\
6a semana - \\
avaliação \\
final e follow \\
up em \\
$3,6,9,12$ \\
meses) \\
\end{tabular} & $\begin{array}{l}\text { A acupuntura } \\
\text { parece ser tão } \\
\text { eficaz quanto a } \\
\text { terapia } \\
\text { medicamentosa } \\
\text { em pacientes } \\
\text { com câncer de } \\
\text { mama que } \\
\text { apresentam } \\
\text { sintomas } \\
\text { vasomotores e } \\
\text { pode fornecer } \\
\text { benefícios } \\
\text { adicionais e de } \\
\text { longo prazo sem } \\
\text { efeitos adversos. }\end{array}$ \\
\hline $\begin{array}{l}\text { de VALOIS } \\
\text { et al. } 2010^{(19)}\end{array}$ & \begin{tabular}{|c|} 
Explorar se \\
acupuntura \\
poderia \\
reduzir a \\
frequência de \\
fogachos e \\
suor noturno, \\
melhorar o \\
bem-estar \\
físico e \\
emocional e \\
melhorar as \\
percepções de \\
fogachos e \\
suor noturno.
\end{tabular} & 50 mulheres & $\begin{array}{l}\text { Acupuntura } \\
\text { sistêmica }\end{array}$ & // & \begin{tabular}{|c|} 
Diários de \\
fogachos - \\
frequências de \\
fogachos e suor \\
noturno; \\
Women's Health \\
Questionnaire - \\
bem-estar físico e \\
emocional; Hot \\
Flashes e Night \\
Sweats \\
Questionnaire - \\
fogachos e suor \\
noturno como \\
um problema.
\end{tabular} & $\begin{array}{c}05 \text { (linha de } \\
\text { base, no meio } \\
\text { do } \\
\text { tratamento, } \\
\text { no fim do } \\
\text { tratamento e } \\
4 \text { e } 18 \\
\text { semanas de } \\
\text { follow up) }\end{array}$ & $\begin{array}{c}\text { Além da redução } \\
\text { da frequência de } \\
\text { fogachos e suor } \\
\text { noturno, as } \\
\text { mulheres } \\
\text { desfrutaram de } \\
\text { um bem-estar } \\
\text { físico e emocional } \\
\text { melhorado, e } \\
\text { poucos efeitos } \\
\text { colaterais foram } \\
\text { relatados. }\end{array}$ \\
\hline $\begin{array}{l}\text { HERVIK; } \\
\text { MJÅLAND, } \\
\text { 2009(17) }\end{array}$ & $\begin{array}{c}\text { Investigar a } \\
\text { eficácia da } \\
\text { acupuntura } \\
\text { em mulheres } \\
\text { com câncer de } \\
\text { mama com } \\
\text { ondas de calor } \\
\text { como } \\
\text { resultado de } \\
\text { medicação } \\
\text { anti- } \\
\text { estrogênio. }\end{array}$ & 59 mulheres & $\begin{array}{l}\text { Acupuntura } \\
\text { sistêmica }\end{array}$ & $\begin{array}{c}\text { Acupuntura sham } \\
\text { (foi realizada com } \\
\text { agulhas idênticas, } \\
\text { inseridas apenas } \\
\text { com 2-3 mm de } \\
\text { profundidade em } 8 \\
\text { pontos, longe dos } \\
\text { pontos de } \\
\text { acupuntura e dos } \\
\text { pontos-gatilho. }\end{array}$ & $\begin{array}{c}\text { Número de ondas } \\
\text { de calor; } \\
\text { Kupperman Index } \\
\text { - ondas de calor, } \\
\text { sudorese, } \\
\text { problemas de } \\
\text { sono, depressão, } \\
\text { cansaço, } \\
\text { tonturas, } \\
\text { palpitações, dor } \\
\text { nas articulações, } \\
\text { dor de cabeça, } \\
\text { secura vaginal e } \\
\text { outros problemas } \\
\text { (os pacientes } \\
\text { devem } \\
\text { especificar). } \\
\end{array}$ & \begin{tabular}{|c|} 
\\
03 (linha de \\
base, ao final \\
do \\
tratamento, \\
3 meses de \\
follow up) \\
\end{tabular} & $\begin{array}{c}\text { A acupuntura } \\
\text { parece } \\
\text { proporcionar } \\
\text { alívio efetivo das } \\
\text { ondas de calor } \\
\text { em mulheres } \\
\text { operadas para } \\
\text { câncer de mama, } \\
\text { tratadas com } \\
\text { tamoxifeno. Este } \\
\text { efeito parece } \\
\text { coincidir com } \\
\text { uma melhoria } \\
\text { geral de saúde } \\
\text { medida com o } \\
\text { índice de } \\
\text { Kupperman. } \\
\end{array}$ \\
\hline
\end{tabular}


Na Figura 3, apresentam-se informações relacionadas ao protocolo de aplicação da acupuntura para os fogachos, conforme recomendações do Revised Standards for Reporting Interventions in Clinical Trials of Acupuncture (STRICTA).
Dentre os estudos selecionados, $27,3 \%$ $(n=3)$ apresentaram nível de evidência II $^{(15,18-19)} \mathrm{e}$ $72,7 \%(n=8)$ apresentam nível de evidência II ${ }^{(4,11-}$ 14,16-17,20).

Figura 3 - Protocolo de intervenção de acordo com o STRICTA. Belo Horizonte, 2019. $(n=11)$

\begin{tabular}{|c|c|c|c|c|c|c|c|c|}
\hline $\begin{array}{c}\text { Identificação } \\
\text { do estudo }\end{array}$ & $\begin{array}{c}\text { Acupontos } \\
\text { utilizados }\end{array}$ & $\begin{array}{c}\text { Referencial } \\
\text { que norteou a } \\
\text { escolha dos } \\
\text { pontos }\end{array}$ & $\begin{array}{l}\text { Dispositivo de } \\
\text { aplicação }\end{array}$ & $\begin{array}{l}\text { Detalhes do } \\
\text { agulhamento }\end{array}$ & $\begin{array}{c}\text { Número } \\
\text { de sessões }\end{array}$ & \begin{tabular}{|} 
Duração \\
da \\
sessão
\end{tabular} & $\begin{array}{c}\text { Frequência } \\
\text { do } \\
\text { tratamento }\end{array}$ & \begin{tabular}{|} 
Profissional \\
que realizou a \\
intervenção e \\
anos de \\
experiência \\
\end{tabular} \\
\hline $\begin{array}{l}\text { LESI et al. } \\
2016^{(20)}\end{array}$ & $\begin{array}{c}\text { BP6, VC4, IG } 11 \\
\text { / Em alguns } \\
\text { casos, pontos } \\
\text { suplementa-res } \\
\text { foram } \\
\text { punturados, } \\
\text { até um máximo } \\
\text { de } 11 \text { pontos } \\
\text { para cada } \\
\text { sessão / } \\
\text { moxabustão } \\
\text { também foi } \\
\text { aplicada, se } \\
\text { necessário }\end{array}$ & 5 & $\begin{array}{l}\text { Agulhas estéreis } \\
\text { e descartáveis } \\
0.30 \times 0.40 \mathrm{~mm} \\
\text { (Suzhou Huanqiu } \\
\text { Acupuncture } \\
\text { Medical } \\
\text { Appliance, } \\
\text { Suzhou, People's } \\
\text { Republic of } \\
\text { China) }\end{array}$ & $\begin{array}{c}\text { Agulhas foram } \\
\text { inseridas } \\
\text { bilateralmente a } \\
\text { uma } \\
\text { profundidade de } \\
0,5 \text { a } 1 \mathrm{~cm} \text { na } \\
\text { maioria das } \\
\text { áreas, exceto no } \\
\text { quadril, onde a } \\
\text { profundidade foi } \\
\text { de } 1 \text { a } 2 \mathrm{~cm} \text {. Elas } \\
\text { foram } \\
\text { manipuladas } \\
\text { manualmente } \\
\text { para provocar a } \\
\text { sensação de Qi. } \\
\text { Nenhum estímulo } \\
\text { ou rotação da } \\
\text { agulha ocorreu } \\
\text { uma vez que foi } \\
\text { inserida. }\end{array}$ & 10 & $\begin{array}{c}20 \\
\text { minutos }\end{array}$ & $1 x /$ semana & \begin{tabular}{|} 
Acupunturistas, \\
que foram \\
treinados e \\
tinham pelo \\
menos 20 anos \\
de experiência \\
clínica.
\end{tabular} \\
\hline $\begin{array}{l}\text { MAO et al. } \\
2015^{(12)}\end{array}$ & \begin{tabular}{|c|} 
Para EA, o \\
acupunturista \\
escolheu \\
pontos padrão \\
dependendo \\
das posições \\
preferidas dos \\
sujeitos. E, até \\
4 pontos foram \\
escolhidos com \\
base em outros \\
sintomas \\
apresentados \\
pelos \\
indivíduos.
\end{tabular} & 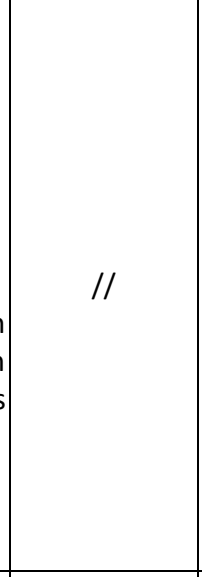 & $\begin{array}{c}\text { Agulhas } \\
0.25 \times 30 \mathrm{~mm} \text { ou } \\
0.25 \times 40 \mathrm{~mm} \\
\text { (Seirin-America, } \\
\text { Weymouth, MA) } \\
\text { / Corrente } \\
\text { bilateral de } 2 \mathrm{~Hz} \\
\text { conectada entre } \\
2 \text { pontos de } \\
\text { acupuntura } \\
\text { usando uma } \\
\text { unidade de } \\
\text { estimulação } \\
\text { elétrica nervosa } \\
\text { transcutânea. }\end{array}$ & $\begin{array}{l}\text { As agulhas foram } \\
\text { inseridas e } \\
\text { manipuladas até } \\
\text { que o De qi }\end{array}$ & 10 & $\begin{array}{c}30 \\
\text { minutos }\end{array}$ & $\begin{array}{c}2 x / \text { semana } \\
\text { durante } 2 \\
\text { semanas. } \\
\text { Posterior- } \\
\text { mente, } \\
1 x / \text { semana } \\
\text { durante } 6 \\
\text { semanas. }\end{array}$ & $\begin{array}{c}2 \\
\text { acupunturistas } \\
\text { não-médicos } \\
\text { licenciados com } \\
8 \text { e } 20 \text { anos de } \\
\text { experiência. }\end{array}$ \\
\hline $\begin{array}{l}\text { BAO et al. } \\
2014^{(13)}\end{array}$ & \begin{tabular}{|c|} 
VC4, VC6, \\
VC12, IG4, CS6, \\
VB34, E36, R3, \\
B65. \\
\end{tabular} & // & // & // & // & // & 8 semanas & // \\
\hline $\begin{array}{l}\text { BOKMAND; } \\
\text { FLYGER, } \\
2013^{(16)}\end{array}$ & $\begin{array}{c}\text { CS6, R3, BP6, } \\
\text { F3 }\end{array}$ & $\begin{array}{c}\text { Os pontos } \\
\text { foram } \\
\text { selecionados } \\
\text { no livro } \\
\text { Practice of } \\
\text { Acupuncture. }\end{array}$ & $\begin{array}{l}\text { Agulhas de } \\
\text { acupuntura }\end{array}$ & // & 5 & $\begin{array}{c}15-20 \\
\text { minutos }\end{array}$ & $1 x /$ semana & $\begin{array}{c}2 \\
\text { acupunturistas } \\
\text { experientes. }\end{array}$ \\
\hline
\end{tabular}




\begin{tabular}{|c|c|c|c|c|c|c|c|c|}
\hline $\begin{array}{c}\text { Identificação } \\
\text { do estudo }\end{array}$ & $\begin{array}{l}\text { Acupontos } \\
\text { utilizados }\end{array}$ & $\begin{array}{c}\text { Referencial } \\
\text { que norteou } \\
\text { a escolha dos } \\
\text { pontos }\end{array}$ & $\begin{array}{l}\text { Dispositivo de } \\
\text { aplicação }\end{array}$ & $\begin{array}{l}\text { Detalhes do } \\
\text { agulhamento }\end{array}$ & $\begin{array}{l}\text { Número } \\
\text { de } \\
\text { sessões }\end{array}$ & $\begin{array}{c}\text { Duração } \\
\text { da } \\
\text { sessão }\end{array}$ & $\begin{array}{c}\text { Frequência } \\
\text { do } \\
\text { tratamento }\end{array}$ & $\begin{array}{c}\text { Profissional } \\
\text { que realizou a } \\
\text { intervenção e } \\
\text { anos de } \\
\text { experiência }\end{array}$ \\
\hline $\begin{array}{c}\text { JEONG et al. } \\
2013^{(18)}\end{array}$ & $\begin{array}{l}\text { VG20, } \\
\text { Yintang, C8, } \\
\text { R10, F2 }\end{array}$ & $\begin{array}{c}\text { Os pontos } \\
\text { foram } \\
\text { selecionados } \\
\text { de acordo } \\
\text { com as } \\
\text { recomenda- } \\
\text { ções dos } \\
\text { especialistas } \\
\text { clínicos em } \\
\text { Medicina } \\
\text { Tradicional } \\
\text { Koreana e } \\
\text { livros-padrão } \\
\text { de } \\
\text { acupuntura. }\end{array}$ & $\begin{array}{l}\text { Agulhas de aço } \\
\text { inoxidável } \\
\text { estéreis e } \\
\text { descartáveis de } \\
0.25 \times 30 \mathrm{~mm} \\
\text { (Dong bang } \\
\text { Acupuncture } \\
\text { Inc., Chung } \\
\text { cheongna-do, } \\
\text { Coréia) }\end{array}$ & $\begin{array}{c}\text { Um total de oito } \\
\text { agulhas foram } \\
\text { usadas. } \\
\text { Dependendo dos } \\
\text { pontos } \\
\text { selecionados, as } \\
\text { agulhas foram } \\
\text { inseridas a 10- } \\
20 \mathrm{~mm} \text { de } \\
\text { profundidade na } \\
\text { pele e foram } \\
\text { gentilmente } \\
\text { manipuladas } \\
\text { para obter De qi. } \\
\text { Após } 10 \\
\text { minutos, as } \\
\text { posições da } \\
\text { agulha foram } \\
\text { controladas por } \\
\text { rotação suave } \\
\text { sem evocar a } \\
\text { sensação de De } \\
\text { qi. }\end{array}$ & 12 & $\begin{array}{c}20 \pm 5 \\
\text { minutos }\end{array}$ & $3 x /$ semana & $\begin{array}{c}\text { Médico } \\
\text { tradicional } \\
\text { coreano com } \\
\text { pelo menos } 3 \\
\text { anos de } \\
\text { experiência } \\
\text { clínica em } \\
\text { tratamento } \\
\text { com } \\
\text { acupuntura. }\end{array}$ \\
\hline $\begin{array}{c}\text { FRISK et al. } \\
2012^{(4)}\end{array}$ & $\begin{array}{l}\text { B15; B23; } \\
\text { B32; VG20; } \\
\text { C7, CS6, F3, } \\
\text { BP6, BP9 }\end{array}$ & MTC & $\begin{array}{c}\text { Agulhas de } \\
0.25 \times 15 \mathrm{~mm} \text { ou } \\
0.30 \times 30 \mathrm{~mm} \\
\text { (Hwato, Suzhou } \\
\text { Medical } \\
\text { Instruments, } \\
\text { China) }\end{array}$ & \begin{tabular}{|} 
Profundidade de \\
inserção: 5 -20 \\
mm. Respostas \\
solicitadas: De qi. \\
Estimulação \\
manual ou \\
elétrica $(2 \mathrm{~Hz})$
\end{tabular} & 14 & $\begin{array}{c}30 \\
\text { minutos }\end{array}$ & $\begin{array}{c}2 \mathrm{x} / \text { semana } \\
\text { durante as } \\
\text { primeiras } 2 \\
\text { semanas. } \\
\text { Posterior- } \\
\text { mente, } \\
1 \mathrm{x} / \text { semana } \\
\text { durante } 10 \\
\text { semanas. }\end{array}$ & $\begin{array}{c}6 \\
\text { fisioterapeutas } \\
\text { com muitos } \\
\text { anos de } \\
\text { experiência. }\end{array}$ \\
\hline $\begin{array}{c}\text { LILJEGREN } \\
\text { et al. 2012 }\end{array}$ & $\begin{array}{l}\text { IG4, C6, F3, } \\
\text { E36, BP6, R7 }\end{array}$ & $\begin{array}{c}\text { Os pontos } \\
\text { foram } \\
\text { selecionados } \\
\text { de acordo } \\
\text { com } \\
\text { relatórios } \\
\text { anteriores e } \\
\text { com opiniões } \\
\text { de } \\
\text { especialistas, } \\
\text { conforme } \\
\text { encontrado } \\
\text { em livros- } \\
\text { texto de } \\
\text { acupuntura }\end{array}$ & $\begin{array}{c}\text { Agulhas } \\
\text { descartáveis } \\
\text { esterilizadas de } \\
0.25 \times 40 \mathrm{~mm} \\
\text { (Dong bang } \\
\text { acupuncture } \\
\text { inc.) }\end{array}$ & \begin{tabular}{|} 
As agulhas foram \\
inseridas a uma \\
profundidade de \\
5 a 20mm e até \\
o paciente sentir \\
a sensibilidade \\
De qi. Este \\
procedimento foi \\
realizado na \\
inserção e na \\
remoção das \\
agulhas. Após 10 \\
min, a posição \\
das agulhas foi \\
controlada por \\
rotação suave \\
sem evocar a \\
sensação de De \\
qi.
\end{tabular} & 10 & $\begin{array}{c}20 \\
\text { minutos }\end{array}$ & $2 x /$ semana & $\begin{array}{l}\text { Fisioterapeuta } \\
\text { oncológico } \\
\text { autorizado com } \\
5 \text { anos de } \\
\text { prática em } \\
\text { acupuntura } \\
\text { para dor, } \\
\text { ondas de calor } \\
\text { e suor. }\end{array}$ \\
\hline
\end{tabular}




\begin{tabular}{|c|c|c|c|c|c|c|c|c|}
\hline $\begin{array}{c}\text { Identificação } \\
\text { do estudo }\end{array}$ & $\begin{array}{l}\text { Acupontos } \\
\text { utilizados }\end{array}$ & $\begin{array}{c}\text { Referencial } \\
\text { que norteou } \\
\text { a escolha dos } \\
\text { pontos }\end{array}$ & $\begin{array}{l}\text { Dispositivo de } \\
\text { aplicação }\end{array}$ & $\begin{array}{l}\text { Detalhes do } \\
\text { agulhamento }\end{array}$ & $\begin{array}{l}\text { Número de } \\
\text { sessões }\end{array}$ & $\begin{array}{c}\text { Duração } \\
\text { da } \\
\text { sessão }\end{array}$ & $\begin{array}{c}\text { Frequência } \\
\text { do } \\
\text { tratamento }\end{array}$ & $\begin{array}{c}\text { Profissional } \\
\text { que realizou a } \\
\text { intervenção e } \\
\text { anos de } \\
\text { experiência }\end{array}$ \\
\hline $\begin{array}{l}\text { OTTE et al. } \\
2011^{(15)}\end{array}$ & \begin{tabular}{|} 
De acordo \\
com \\
diagnóstico \\
da MTC de \\
cada \\
indivíduo. Os \\
pontos mais \\
frequentes \\
foram \\
estavam \\
localizados no \\
meridiano do \\
pulmão.
\end{tabular} & MTC & $\begin{array}{l}\text { Agulhas de } \\
\text { acupuntura }\end{array}$ & $\begin{array}{l}\text { Utilizou-se } \\
\text { uma média } \\
\text { de } 10 \text { agulhas } \\
\text { por sessão }\end{array}$ & 3 & // & // & \begin{tabular}{|c} 
Acupunturistas \\
licenciados \\
com pelo \\
menos 6 anos \\
de experiência. \\
Possuíam \\
mestrado em \\
medicina \\
oriental em \\
uma escola \\
americana \\
credenciada e \\
eram membros \\
da organização \\
profissional \\
local e nacional \\
para \\
acupunturistas.
\end{tabular} \\
\hline $\begin{array}{c}\text { WALKER } \\
\text { et al. 2010 }\end{array}$ & \begin{tabular}{|} 
B23, R3, BP, \\
VG 14, VB20, \\
P9, F3, VG20, \\
E36, VC6, \\
CS7, C7
\end{tabular} & MTC & $\begin{array}{c}\text { Agulhas de aço } \\
\text { inoxidável } \\
\text { filiforme de } 0.20 \\
\text { x } 30 \mathrm{~mm} \\
\text { (Seirin; Shizuoka } \\
\text { City, Japão; e } \\
\text { Carbo, Toronto, } \\
\text { Canadá). }\end{array}$ & $\begin{array}{c}\text { Agulhas } \\
\text { foram } \\
\text { inseridas } 0,25 \\
\text { a } 0,5 \\
\text { polegadas de } \\
\text { profundidade } \\
\text { na pele e } \\
\text { manipuladas } \\
\text { para criar a } \\
\text { sensação De } \\
\text { qi }\end{array}$ & 16 & $\begin{array}{c}30 \\
\text { minutos }\end{array}$ & $\begin{array}{c}2 x / \text { semana } \\
\text { durante as } \\
\text { primeiras } 4 \\
\text { semanas. } \\
\text { Posterior- } \\
\text { mente, } \\
\text { 1x/semana } \\
\text { durante } 8 \\
\text { semanas. }\end{array}$ & // \\
\hline $\begin{array}{c}\text { de VALOIS } \\
\text { et al. 2010(19) }\end{array}$ & \begin{tabular}{|c} 
Tratamento 1 \\
(Drenagem \\
de energia \\
agressiva); \\
B13, B14, \\
B15. B18. \\
B20, B23. \\
Tratamento 2 \\
(Tratar as \\
ondas de \\
calor e suores \\
noturnos): \\
P7, R6, VC4, \\
BP6, R7, \\
IG11. Havia \\
também a \\
opção de usar \\
pontos \\
individuais.
\end{tabular} & 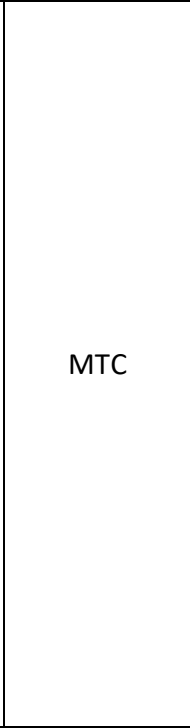 & $\begin{array}{l}\text { Agulhas de } \\
\text { acupuntura }\end{array}$ & $\begin{array}{c}\text { Para cada } \\
\text { ponto, foi } \\
\text { apresentada } \\
\text { uma } \\
\text { orientação }\end{array}$ & 8 & $\begin{array}{c}20 \\
\text { minutos } \\
\text { (com a } \\
\text { agulha)/ } \\
\text { sessões } \\
\text { de uma } \\
\text { hora }\end{array}$ & $1 x /$ semana & Acupunturistas \\
\hline
\end{tabular}




\begin{tabular}{|c|c|c|c|c|c|c|c|c|}
\hline $\begin{array}{l}\text { Identificação } \\
\text { do estudo }\end{array}$ & $\begin{array}{l}\text { Acupontos } \\
\text { utilizados }\end{array}$ & $\begin{array}{c}\text { Referencial } \\
\text { que norteou } \\
\text { a escolha dos } \\
\text { pontos }\end{array}$ & $\begin{array}{c}\text { Dispositivo de } \\
\text { aplicação }\end{array}$ & $\begin{array}{l}\text { Detalhes do } \\
\text { agulhamento }\end{array}$ & $\begin{array}{l}\text { Número } \\
\text { de } \\
\text { sessões }\end{array}$ & \begin{tabular}{|} 
Duração \\
da \\
sessão
\end{tabular} & $\begin{array}{c}\text { Frequência } \\
\text { do } \\
\text { tratamento }\end{array}$ & $\begin{array}{c}\text { Profissional } \\
\text { que realizou a } \\
\text { intervenção e } \\
\text { anos de } \\
\text { experiência } \\
\end{array}$ \\
\hline $\begin{array}{l}\text { HERVIK; } \\
\text { MJÅLAND, } \\
\text { 2009(17) }\end{array}$ & $\begin{array}{l}\text { F3, VB20, P7, } \\
\text { R3, BP6, VC7, } \\
\text { CS7, F8 }\end{array}$ & MTC & $\begin{array}{c}\text { Agulhas } \\
\text { descartáveis } \\
\text { de } 0.30 \mathrm{~mm}\end{array}$ & \begin{tabular}{|} 
Os pontos foram \\
inseridos \\
unilateralmente. \\
Agulhas foram \\
manipuladas \\
manualmente no \\
início e no final de \\
cada tratamento até \\
que o paciente \\
relatasse a sensação \\
de $D e$ qi.
\end{tabular} & 10 & $\begin{array}{c}30 \\
\text { minutos }\end{array}$ & $2 x /$ semana & $\begin{array}{c}\text { Fisioterapeuta } \\
\text { com um curso } \\
\text { de treinamento } \\
\text { certificado de } 3 \\
\text { anos da Escola } \\
\text { Norueguesa de } \\
\text { Acupuntura e } \\
15 \text { anos de } \\
\text { prática. }\end{array}$ \\
\hline
\end{tabular}

Nota: MTC - Medicina Tradicional Chinesa; EA - eletroacupuntura; VG - Vaso governador; VC - Vaso concepção; BP - Baço-pâncreas; E - estômago; P- Pulmão; IG - Intestino delgado; F - Fígado; VB - Vesícula biliar; R - Rim; B - Bexiga; CS - Circulação sexo; C - Coração; $\mathrm{mm}$ - milímetros; $\mathrm{Hz}-\mathrm{Hertz}$.

A acupuntura apresentou-se como uma estratégia eficaz para o alívio dos fogachos em mulheres após câncer de mama. Foi observada, ainda, melhora da qualidade de vida ${ }^{(4,20)}$, bem como do estado geral de saúde ${ }^{(17)}$ e do bem-estar físico e emocional dessa população ${ }^{(19)}$. Destaca-se, também, que os distúrbios de sono, característicos em algumas mulheres, em decorrência dos suores noturnos consequentes dessa condição, apresentaram uma redução significativa frente à intervenção da acupuntura $^{(4,15-16)}$.

No que concerne à nacionalidade dos estudos, verifica-se que nenhum foi realizado no Brasil. Tal fato demonstra a escassez da temática na produção brasileira. Corroborando essa afirmação, por meio de revisão integrativa da literatura, cujo objetivo foi analisar a produção científica nacional sobre o uso das Práticas Integrativas e Complementares em saúde, dentre as quais a acupuntura está inserida, evidenciou-se que, embora tenha ocorrido um aumento do número da produção científica no Brasil, apenas $10 \%$ adota estudos experimentais como método de pesquisa ${ }^{(21)}$. Assim, em nível nacional, a discussão sobre a eficácia da acupuntura no tratamento dos sintomas de fogachos em mulheres que tiveram câncer de mama ainda é incipiente.

Em contrapartida, a literatura internacional apresenta um maior número de publicações sobre a acupuntura no tratamento de fogachos. Observou-se que, dentre os achados desse estudo, $27,3 \%(15,18-19)$ são de nível de evidência III e $72,7 \%^{(4,11-14,16-17,20)}$ de nível de evidência II.

Em relação à modalidade da acupuntura utilizada no grupo experimental, $81,8 \%$ dos estudos adotaram a sistêmica ${ }^{(11,13-20)}$ e $18,2 \%$ utilizaram também a eletroacupuntura ${ }^{(4,12)}$. Os resultados foram positivos em ambas as práticas adotadas, disso pode se inferir que os dois tipos de modalidade da acupuntura são eficientes para o alívio dos fogachos e os desconfortos associados.

Quanto ao grupo controle, houve variação de técnicas empregadas. Contudo, a acupuntura sham (aplicada em pontos que não têm relação com o foco de investigação) foi utilizada em $62,5 \%$ estudos $^{(11-13,16-17)}$. O método sham como placebo na acupuntura é utilizado, porém apresenta-se como uma grande barreira, uma vez que há dificuldade em caracterizá-lo como totalmente inativo ${ }^{(22)}$.

Nessa perspectiva, Liljegren e colaboradores (2012) avaliaram a ação da acupuntura verdadeira em comparação com a estimulação não insertiva em não pontos de acupuntura (CTRL) sobre os fogachos e suores em mulheres diagnosticadas com câncer de mama tratado com tamoxifeno como adjuvante. Embora os resultados sejam significativos no sentido de que a acupuntura real é mais eficaz que o placebo, ainda é possível identificar que a CTRL possibilita um efeito considerável quando comparada a outras terapias e, portanto, não deve ser utilizada como placebo em estudos nessa vertente.

Dentre os estudos selecionados, observouse que $45,4 \%^{(12,15-16,19-20)}$ tiveram a intervenção executada por acupunturistas que tinham de seis $^{(15)}$ a $20^{(12,20)}$ anos de experiência na área clínica. A acupuntura foi realizada também por um médico tradicional coreano ${ }^{(18)}$ e fisioterapeutas com experiência na área de acupuntura ${ }^{(4,11,17)}$. Apenas $18,2 \%^{(13-14)}$ não referiram a formação dos profissionais que praticaram a intervenção. 
A experiência e a prática do profissional intervencionista são de fundamental importância na condução da acupuntura. Segundo as recomendações do STRICTA (2010), a escolha e a descrição da prática do profissional podem reduzir o viés de experiência e implicarão na melhor aplicabilidade dos resultados.

É importante destacar que não foi observada padronização no protocolo para o alívio dos fogachos no que diz respeito aos pontos de aplicação, número e duração das sessões de acupuntura. Nos achados, o número de sessões variou de três ${ }^{(15)}$ a 16 sessões ${ }^{(14)}$, sendo um número médio de 10 sessões, no período de uma $^{(16,19-20)}$ a três vezes por semana ${ }^{(18)}$, com a retenção das agulhas no corpo por, aproximadamente, 25 minutos. Ressalta-se que estes foram determinados, a partir da média aritmética de cada estudo selecionado na presente revisão e o profissional pode adequar números de acordo com a necessidade de cada paciente.

Salienta-se que a padronização por meio de um protocolo em estudos de intervenção é necessária para garantir a replicabilidade do mesmo, o que é essencial para a prática baseada em evidências ${ }^{(23)}$.

No entanto, a revisão retrospectiva das associações entre os sintomas relatados pelo paciente e o diagnóstico de MTC em resposta ao tratamento com acupuntura às ondas de calor em pacientes com câncer evidenciaram que há a possibilidade de realizar a individualidade do tratamento por meio de um diagnóstico de acordo com os princípios da MTC. Essa constatação abre a possibilidade para a versatilidade de acupontos em cada sessão, conforme os agrupamentos de sintomas e a alteração da avaliação clínica, minimizando a ideia de uma intervenção por meio de protocolos pré-fixados com base apenas no diagnóstico presumido do sintoma principal, desconsiderando os sintomas associados ${ }^{(24)}$.

Quanto ao referencial teórico que norteou a conduta terapêutica para o tratamento dos fogachos por meio da acupuntura, $54,5 \%$ dos estudos $^{(4,14-15,17,19-20)}$ utilizaram os preceitos da MTC. Nos demais, os autores relatam ter baseado a seleção dos acupontos em livros de acupuntura $^{(11,16,18)}$ e apenas $18,8 \%$ não reportam tal informação(12-13).

Dentre os acupuntos mais utilizados nos estudos que fizeram parte dessa revisão, destacam-se: o BP6, que foi empregado em $63,3 \%$ dos estudos ${ }^{(4,11,14,16-17,19-20)}$; o F3 em $45,4 \%^{(4,11,14,16-}$
17); o R3 em $36,3 \% \%^{(13-14,16-17)}$; o CS6 $6^{(4,13,16)}$, o VC4 ${ }^{(13,19-}$ 20), O $B 23^{(4,14,19)}$ e o $\operatorname{VG} 20^{(4,14,18)}$, que foram utilizados em $27,3 \%$ dos estudos.

Referente ao dispositivo de aplicação da acupuntura, predominou o uso de agulhas sistêmicas, que foram utilizadas em $90,9 \%$ dos estudos $^{(4,11-12,14-18,20)}$; um estudo ${ }^{(13)}$ não trouxe essa informação, o que compromete a sua replicabildade. Destaca-se, ainda, que em $63,6 \%$ dos estudos ${ }^{(4,11-12,14,17-18,20)}$, os autores relataram manipulação das agulhas, até alcançar a sensação de $D e$ qi; dois estudos ${ }^{(4,12)}$ também utilizaram a estimulação elétrica.

O termo acupuntura deriva do latim, em que acus significa agulha e punctura é o mesmo que puncionar. Dentre os dispositivos usados na acupuntura, as agulhas são os mais utilizados mundialmente e são aqueles que desencadeiam os resultados mais promissores. Quando inseridas em um acuponto e manipuladas, evocam uma sensação chamada De qi, que significa "chegada do $Q i^{\prime \prime(25)}$, e é descrita como dor, dormência, formigamento, peso, plenitude, calor, distensão ou pressão ${ }^{(26)}$. Acredita-se que resultados positivos estão associados à sensação do "De qi". De fato, o estudo que explorou a relação entre o De qi e a eficácia clínica da acupuntura para dismenorreia primária apontou que essa sensação contribuiu para o efeito analgésico da intervenção; além disso, foi reportado que a manipulação manual da agulha é um pré-requisito para se obter e aprimorar as sensações de "De qi", e este é fundamental para alcançar efeitos terapêuticos ${ }^{(26)}$.

Atualmente, alguns dispositivos não invasivos têm sido adotados para estimular os pontos de acupuntura, como, por exemplo, o laser, o haihua (estimulação eletromagnética), as sementes, os cristais, os magnetos, dentre outros. Destaca-se que esses dispositivos podem potencializar os efeitos desencadeados pelas agulhas; contudo a ação da agulha é mais potente quando comparada à aplicação desses dispositivos isoladamente ${ }^{(27)}$. Ressalta-se que, até o presente momento, não foram encontrados estudos que comparassem os efeitos de estímulos invasivos e não invasivos da acupuntura sobre os fogachos em mulheres após câncer de mama; acredita-se, todavia, que melhores resultados podem ser encontrados com a utilização de agulhas. Contudo, investigações são necessárias para confirmar tal hipótese.

Por outro lado, a estimulação elétrica, quando associada às agulhas de acupuntura, 
parece intensificar os efeitos desencadeados pela intervenção. Na presente revisão, apenas dois estudos $^{(4,12)}$ utilizaram esse tipo de estimulação; contudo, nenhum deles comparou os efeitos da eletroacupuntura aos efeitos da estimulação manual com evocação de "De qi" nessa população. Em outras, como em pessoas com lombalgia crônica, melhores resultados foram encontrados para o grupo que recebeu a acupuntura com estímulo elétrico em comparação ao grupo que recebeu a intervenção apenas com o estímulo manual|(28-29). Novamente, para comprovar tal hipótese em mulheres com fogachos, estudos adicionais com amostras expressivas se fazem necessários.

\section{CONCLUSÃO}

A acupuntura parece ser uma intervenção efetiva para o tratamento e controle dos fogachos em mulheres após câncer de mama. Todavia, a variedade nos estudos pode comprometer os achados.

Ressalta-se que não houve uma padronização no tratamento de acupuntura para o alívio dos fogachos em relação aos pontos de aplicação, número e duração das sessões. Apesar disso, um possível protocolo pode ser proposto para essa condição clínica, a partir dos estudos levantados: realização da acupuntura sistêmica ou eletroacupuntura nos acupontos BP6, F3, R3, CS6, VC4, B23 e VG20, com agulhas sistêmicas, que devem ser manipuladas até obter-se a sensação de "De qi", em 10 sessões, uma ou duas vezes por semana, com retenção das agulhas nos acupontos em aproximadamente 25 minutos. Destaca-se, também, que a avaliação individualizada a cada sessão é importante, podendo novos pontos ser acrescentados a esses pontos principais.

Como limitação deste estudo, destaca-se que bases de dados chinesas não foram consultadas. Como a acupuntura é prática clínica comum no país, mais estudos poderiam ter sido resgatados. Outro evento que pôde atuar como fator limitante é a restrição de idiomas, uma vez que estudos em outras línguas podem ter sido perdidos no momento da seleção de busca desse estudo.

Sugere-se, portanto, a realização de ensaios clínicos randomizados com a utilização do protocolo proposto no presente estudo, a fim de validá-lo, uma vez que as evidências científicas sobre a utilização da acupuntura para os fogachos em mulheres após câncer de mama ainda são insipientes e esses estudos são essenciais para comprovar a eficácia de intervenções clínicas na área da saúde.

Como importante implicação para a prática, ressalta-se que a acupuntura é uma opção terapêutica para a redução dos sintomas de fogachos em mulheres após câncer de mama. Essa prática permite ao enfermeiro atuar de maneira autônoma e independente em todos os níveis de atenção, promovendo cuidado e assistência às mulheres nessas condições.

\section{REFERÊNCIAS}

1- World Health Organization (WHO). Global health observatory. Geneva: World Health Organization; 2018.

2- Bray F, Ferlay J, Soerjomataram I, Siegel RL, Torre LA, Jemal A. Global cancer statistics 2018: GLOBOCAN estimates of incidence and mortality worldwide for 36 cancers in 185 countries. CA Cancer J Clin. 2018;68 (6):394-424. DOI: 10.3322/caac. 21492

3- Tao WW, Jiang $H$, Tao XM, Jiang $P$, Sha $L Y$, Sun $X C$. Effects of acupuncture, Tuina, Tai Chi, Qigong, and Traditional Chinese medicine five-element music therapy on symptom management and quality of life for cancer patients: A meta-analysis. J Pain Symptom Manage. 2016;51(4):728-47. DOI: 10.1016/i.jpainsymman.2015.11.027

4- Frisk J, Källström $A C$, Wall $N$, Fredrikson $M$, Hammar M. Acupuncture improves health-related quality-of-life (HRQoL) and sleep in women with breast câncer and hot flushes. Support Care Cancer. 2012;20 (4):715-24. DOI: 10.1007/s00520011-1134-8

5- Morrow PK, Mattair DN, Hortobagyi GN. Hot flashes: A review of pathophysiology and treatment modalities. Oncologist 2011;16(11):1658-64. DOI: 10.1634/theoncologist.2011-0174

6- Wang G, Litscher G. Acupuncture for Neoplasms: An Update from the PubMed Database. MedAcupunct. 2015;27(3):151-7. DOI: 10.1089/acu.2014.1077

7- Lopes-Júnior CL, Cruz LA, Leopoldo VC, Campos FR, Almeida AM, Silveira RC. Effectiveness of traditional chinese acupuncture versus sham acupuncture: A systematic review. Rev Latino-Am $\begin{array}{lll}\text { Enfermagem 2016;15 (24):e2762. DOI: } & \end{array}$ 10.1590/1518-8345.0647.2762

8- Whittemore R, Knafl K. The integrative review: Updated methodology. J Adv Nurs. 2005;52(5):546-53. DOI: 10.1111/i.1365$\underline{2648.2005 .03621 . x}$ 
9- MacPherson H, Altman DG, Hammerschlag R, Youping L, Taixiang W, White A, et al. Revised Standards for Reporting Interventions in Clinical Trials of Acupuncture (STRICTA): Extending the CONSORT statement. PLOS Med. 2010;7(6):e1000261.

DOI:

10.1371/journal.pmed.1000261

10- Melnyk BM, Fineout-Overholt E. Evidencebased practice in nursing and healthcare: $A$ guide to best practice. 3rd ed. Philadelphia: Lippincott Williams and Wilkins; 2015.

11- Liljegren A, Gunnarsson P, Landgren BM, Robéus $\mathrm{N}$, Johansson $\mathrm{H}$, Rotstein $\mathrm{S}$. Reducing vasomotor symptoms with acupuncture in breast cancer patients treated with adjuvant tamoxifen: A randomized controlled trial. Breast Cancer Res Treat. 2012;135(3):791-8. DOI: 10.1007/s10549010-1283-3

12- Mao JJ, Bowman MA, Xie SX, Bruner D, DeMichele A, Farrar JT. Electroacupuncture versus gabapentin for hot flashes among breast cancer survivors: A randomized placebo-controlled trial. J Clin Oncol. 2015;33 (31):3615-20. DOI: 10.1200/JCO.2015.60.9412

13- Bao T, Cai L, Snyder C, Betts K, Tarpinian K, Gould J, et al. Patient-reported outcomes in women with breast cancer enrolled in a dualcenter, double-blind, randomized controlled trial assessing the effect of acupuncture in reducing aromatase inhibitor-induced musculoskeletal symptoms. Cancer 2014;120(3):381-9. DOI: 10.1002/cncr.28352

14- Walker EM, Rodriguez Al, Kohn B, Ball RM, Pegg J, Pocock JR, et al. Acupuncture versus venlafaxine for the management of vasomotor symptoms in patients with hormone receptorpositive breast cancer: $A$ randomized controlled trial. J Clin Oncol. 2010;28(4):634-40. DOI: 10.1200/JCO.2009.23.5150

15- Otte JL, Carpenter JS, Zhong X, Johnstone PA. Feasibility study of acupuncture for reducing sleep disturbances and hot flashes in postmenopausal breast cancer survivors. Clin Nurse Spec. 2011;25(5):228-36.

DOI:

\subsection{7/NUR.0b013e318229950b}

16- Bokmand S, Flyger H. Acupuncture relieves menopausal discomfort in breast cancer patients: A prospective, double blinded, randomized study. Breast 2013;22(3):320-3. DOI: 10.1016/j.breast.2012.07.015

17- Hervik J, Mjåland $O$. Acupuncture for the treatment of hot flashes in breast cancer patients, a randomized, controlled trial. Breast Cancer Res
Treat. 2009;116(2):311-6. DOI: 10.1007/s10549008-0210-3

18- Jeong YJ, Park YS, Kwon HJ, Shin IH, Bong JG, Park SH. Acupuncture for the treatment of hot flashes in patients with breast cancer receiving antiestrogen therapy: A pilot study in Korean women. J Altern Complement Med. 2013;19(8):690-6. DOI: 10.1089/acm.2012.0347

19- de Valois BA, Young TE, Robinson N, McCourt C, Maher EJ. Using traditional acupuncture for breast cancer-related hot flashes and night sweats. J Altern Complement Med. 2010;16(10):1047-57. $10.1089 / \mathrm{acm} .2009 .0472$

20- Lesi G, Razzini G, Musti MA, Stivanello E, Petrucci $C$, Benedetti $B$, et al. Acupuncture as an integrative approach for the treatment of hot flashes in women with breast cancer: A Prospective Multicenter Randomized Controlled Trial (AcCliMaT). J Clin Oncol. 2016;34(15):1795802. DOI: $10.1200 / J C O .2015 .63 .2893$

21- Reis BO, Esteves LR, Greco RM. Avanços e desafios para a implementação das Práticas Integrativas e Complementares no Brasil. Rev APS 2018;21(3):355-64. DOI: $10.34019 / 1809-$ 8363.2018.v21.16383

22- Zhang CS, Tan HY, Zhang GS, Zhang AL, Xue $\mathrm{CC}, \mathrm{Xie}$ YM. Placebo devices as effective control methods in acupuncture clinical trials: A systematic review. PLoS One 2015;10(11):e0140825. DOI: 10.1371/journal.pone. 0140825

23- Moura CC, Chaves ECL, Cardoso ACLR, Nogueira DA, Azevedo C, Chianca TCM. Auricular acupuncture for chronic back pain in adults: $A$ systematic review and metanalysis. Rev Esc Enferm USP. 2019;53:e03461. DOI: 10.1590/s1980-220x2018021703461

24- Liu W, Qdaisat A, Lopez G, Narayanan S, Underwood S, Spano M, et al. Acupuncture for hot flashes in cancer patients: Clinical characteristics and traditional chinese medicine diagnosis as predictors of treatment response. Integr Cancer Ther. 2019;18:1534735419848494. DOI: 10.1177/1534735419848494

25- Park JE, Ryu YH, Liu Y, Jung HJ, Kim AR, Jung $S Y$, et al. A literature review of de qi in clinical studies. Acupunct Med. 2013;3(2):132-42. DOI: 10.1136/acupmed-2012-010279

26- Xiong J, Liu F, Zhang MM, Wang W, Huang GY. De qi, Not psychological factors, determines the therapeutic efficacy of acupuncture treatment for primary dysmenorrhea. Chin J Integr Med. 
2012;18(1):7-15. DOI: 10.1007/s11655-011-08571

27- Kurebayashi LFS, Gnatta JR, Borges TP, Belisse G, Coca S, Minami A, et al. The applicability of auriculotherapy with needles or seeds to reduce stress in nursing professionals. Rev Esc Enferm USP 2012; 46(1):89-95. Available from: http://dx.doi.org/10.1590/S0080-

\section{2}

28- Sator-Katzenschlager SM, Scharbert G, Kozek-Langenecker SA, Szeles JC, Finster G, Schiesser AW, et al. The short- and long-term benefit in chronic low back pain through adjuvant electrical versus manual auricular acupuncture. Anesth Analg. 2004;98(5):1359-64. DOI: 10.1213/01.ANE.0000107941.16173.F7

29- Sator-Katzenschlager SM, Szeles JC, Scharbert G, Michalek-Sauberer A, Kober A, Heinze $G$, et al. Electrical stimulation of auricular acupuncture points is more effective than conventional manual auricular acupuncture in chronic cervical pain: A pilot study. Anesth Analg. 2003;97(5):1469-73.

DOI: 10.1213/01.ANE.0000082246.67897.0B

Nota: Esta pesquisa foi originada a partir do Trabalho de Conclusão de Curso de Especialização em Acupuntura (Faculdade INCISA/IMAM) de Nazir Felippe Gomes.

Recebido em: 04/03/2020

Aprovado em: 31/07/2020

\section{Endereço de email:}

Bianca Bacelar de Assis

Escola de Enfermagem da Universidade Federal de Minas Gerais. Avenida Professor Alfredo Balena, 190 - Santa Efigênia, Belo Horizonte - MG, 30130-100.

E-mail: bibacelar@hotmail.com 